\title{
A PARTICIPAÇÃO DA MULHER TRABALHADORA COMO ASSOCIADA NO STTR/CAMETÁ E A SUA CONSTITUIÇÃO COMO SER POLÍTICO'1
}

\author{
Eleuza de Souza² \\ Maria Edilene da Silva Ribeiro ${ }^{3}$ \\ Odete da Cruz Mendes ${ }^{4}$
}

\begin{abstract}
Resumo
Este trabalho analisa o papel da mulher agricultora no Sindicato de Trabalhadores e Trabalhadoras, Agricultores e Agricultoras Familiares Rurais (STTR), a fim de compreender os limites da atuação desta e sua constituição de ser politicamente mais engajada. Parte de abordagem qualitativa, ancorada em Netto e Braz (2010), Cisne e Santos (2018), Silva (2008), Aquime (2018), e outros, e da análise documental (recorte temporal de 1997 a 2010). Os resultados demonstram a relevância do sindicato para as ações de suas associadas, e, consequentemente, as contribuições na formação de agente político.

Palavras-chave: Trabalhadora Agricultora Rural; Sindicato Rural; STTR/Cametá; Ser Político.

\section{LA PARTICIPACIÓN DE LA MUJER TRABAJADORA COMO ASOCIADA EN STTR / CAMETÁ Y SU CONSTITUCIÓN COMO SER POLÍTICO}

\section{Resumen}

Este artículo analiza el papel de la mujer agricultora en el Sindicato de Trabajadores Rurales de Cametá (STTR), para comprender los límites de las actividades de la asociada y si se ha convertido en un ser social más comprometido políticamente. Parte de un enfoque cualitativo, anclado en Netto y Braz (2010), Cisne y Santos (2018), Silva (2008), Aquime (2018), entre otros, combinados con el estudio documental (de 1997 a 2010). Los resultados demuestran la importancia del sindicato para las acciones de sus miembros y, en consecuencia, contribuyen a su constitución del ser político.

Palabras clave: Trabajador agrícola rural; Unión rural; STTR / Cametá; Ser político.

\section{THE PARTICIPATION OF WORKING WOMAN AS AN ASSOCIATE IN STTR / CAMETÁ AND ITS CONSTITUTION AS A POLITICAL BEING}

\begin{abstract}
This article analyzes the role of women farmers in the Rural Workers Union (STTR) of Cametá, to understand the limits of the associate's activities and whether she has become a more politically committed social being. Part of a qualitative approach, anchored in Netto and Braz (2010), Cisne and Santos (2018), Silva (2008), Aquime (2018), among others, combined with the documentary study (from 1997 to 2010). The results demonstrate the importance of the union for the actions of its members and, consequently, contribute to its constitution of being political.
\end{abstract}

Keywords: Rural Farming Worker; Rural Union; STTR / Cametá; Being political.

\footnotetext{
${ }^{1}$ Artigo recebido em 30/04/2020. Primeira avaliação em 27/05/2020. Segunda avaliação em 14/07/2020. Terceira avaliação em 16/07/2020. Aprovado em 21/08/2020. Publicado em 25/09/2020.

DOI: https://doi.org/10.22409/tn.v18i37.42473

2 Mestre em Educação pela Universidade Federal do Pará (UFPA) - Brasil. Professora da Educação Básica. Email:_eleuza-souza@bol.com.br. ; ORCID: 0000-0002-8289-1315.

Lattes: http://lattes.cnpq.br/0717847113850558

3 Doutora e Mestre em Educação pela Universidade Federal do Pará (UFPA) - Brasil. Professora da Universidade Federal do Pará - UFPA. E-mail: mariaedileneribeiro@yahoo.com.br ORCID: 0000-0002-0989-0391. Lattes: http://lattes.cnpq.br/6279228695466400

4 Doutora em Educação pela Universidade Federal do Rio Grande do Norte (UFRN) - Brasil. Mestre em Educação pela Universidade Federal do Pará (UFPA) - Brasil. Professora da Universidade Federal do Pará (UFPA). E-mail: ocm@ufpa.br ORCID: 0000-0002-1475-3922 Lattes: http://lattes.cnpq.br/3058470629162300
} 


\section{Introdução}

O presente texto é fruto de uma pesquisa que analisou o papel da mulher agricultora no Sindicato de Trabalhadores Rurais, Agricultores e Agricultoras Familiares de Cametá - STTR/Cametá, antes STR ${ }^{5}$, tendo em vista os limites da sua atuação de associada e as possíveis conquistas, a partir deste movimento sindical que a tornou politicamente mais engajada. Objetiva-se, assim, analisar a relação entre trabalho e constituição da mulher em Ser Político no/pelo trabalho, no contexto das lutas na referida entidade sindical.

Uma vez estabelecido o campo empírico da pesquisa como o Sindicato de Trabalhadores Rurais, Agricultores e Agricultoras Familiares de Cametá STTR/Cametá, no estado do Pará, com sede na referida cidade, definimos um recorte temporal para obtenção dos dados - 1997 a 2010 -, período de interstícios de inserção e ampliação das lideranças no contexto do movimento no qual a mulher trabalhadora passou a ser reconhecida não apenas como associada, mas como liderança da organização, pautando suas demandas e buscando posicionamentos na entidade.

A metodologia constou de revisão da literatura e análise de documentos ${ }^{6} \operatorname{como}$ relatórios de congressos, relatórios de encontros formativos e deliberativos, atas de posse de diretoria do sindicato, fichas de filiação de associados, projetos de formação e relatórios de projetos, entre outros, imprescindíveis para desvelar o processo de organização, participação da mulher trabalhadora na referida entidade.

Justifica-se as técnicas utilizadas por serem adequadas ao tratamento de um tema que envolve sujeitos coletivos e suas experiências sociais, e que suscita, segundo Minayo (1994, p. 21), "[...] um universo de significados, motivos, aspirações, crenças, valores e atitudes, relevantes para compreensão das relações, e processos de vivências dos sujeitos". Ainda de acordo com a autora, só o ser humano é capaz de agir e pensar sobre o que faz, interpretando suas ações dentro e a partir de suas experiências vividas e partilhadas com seus pares.

\footnotetext{
${ }^{5}$ Conforme Ata de Alteração Estatutária do Sindicato dos Trabalhadores Rurais - STR/Cametá, de 18 de dezembro de 2015, a alteração estatutária seria feita na "[...]representação sindical profissional para a categoria de Trabalhadores e Trabalhadoras, Agricultores e Agricultoras Familiares Rurais [...] Estatuto do Sindicato de Trabalhadores Rurais, Agricultores e Agricultoras Familiares de Cametá STTR/Cametá (STTR/CAMETA, 2015, p. 1).

${ }^{6}$ Esclarecemos que os documentos analisados retratam a entidade com a sigla STR/Cametá, uma referência ao atual STTR/Cametá, conforme a anterior nota explicativa.
} 
A importância de documentos como fonte de pesquisa é reiterada por Cellard (2008), que considera "[...] uma fonte preciosa insubstituível em qualquer reconstituição referente a um passado relativamente distante". Além disso, muito frequentemente, ele permanece como "[...] testemunho de atividades particulares ocorridas num passado recente" (CELLARD, 2008, p.295).

Os dados documentais foram fundamentais para a compreensão dos processos participativos e sócio-históricos; nesse caso, em particular, o processo do movimento sindical local e sua relação com inserção das trabalhadoras nesse contexto.

O interesse pelo tema, dentre outros aspectos, se deve à formação política da massa trabalhadora do município por meio do STTR/Subsede Cametá, entidade que congrega inúmeros trabalhadores da região e que, com apoio da Prelazia de Cametá, liderou uma das mais importantes mobilizações da classe trabalhadora, conhecida como "Encontro do Anilzinho"7. Neste recorte de estudo, porém, problematizamos o processo de organização e participação das trabalhadoras agricultoras no contexto do sindicato e os espaços de liderança por elas assumidos, apontando a importância das ações empreendidas como associadas.

Consideramos relevante o presente estudo por ele envolver sujeitos pertencentes a um grupo social excluído, mas que contribui decisivamente para um projeto mais humano de sociedade. Como associadas, seus serviços protagonizam a sobrevivência de sua família, produzindo, ainda que de forma invisível, os conhecimentos no/pelo trabalho e fortalecendo, assim, o movimento social de forma mais politizada e potencialmente plena.

A pertinência do tema como objeto de investigação acadêmico-científica se deve, dentre outros, à importância que a organização sindical assume, nesse caso o STTR/Cametá, na sociedade local, constituindo-se uma entidade de classe na qual homens e mulheres do campo se identificam e protagonizam direitos por meio de lutas

\footnotetext{
7 Segundo Almeida (2010), o movimento do Anilzinho se constitui como um marco histórico do campesinato do Baixo Tocantins. O movimento que aconteceu no município de Baião/PA, em 1979, numa região denominada Anilzinho, situada às margens de um rio do mesmo nome, foi o primeiro no contexto da luta pela tomada do Sindicato dos Trabalhadores Rurais (STR) -, hoje STTR, pelos trabalhadores alinhados politicamente como o "novo sindicalismo". Considerado um fato importante no processo de luta pela terra que já iniciara em diversas regiões do Brasil e sobre a qual a Igreja Católica manifestou publicamente o seu apoio na Conferência Nacional dos Bispos do Brasil, de 1980, lançando o documento "Igreja e problemas da terra". Em decorrência desse acontecimento, foi criada a "Lei Anilzinho" e outras. A Lei dos posseiros 197 é "[...] um conjunto de leis construída por esses sujeitos com a finalidade de proteger as pequenas propriedades do latifúndio" (SILVA, 2018).
} 
diversas. Além desse importante espaço de reconhecimento das identidades rurais, o estudo é um resgate de dados que pode servir para embasamento de futuros estudos e, assim, contribuir com o movimento, como forma de reflexão quanto aos direcionamentos construídos por esses sujeitos, enquanto categoria de trabalhadoras e trabalhadores.

A abordagem do tema no presente artigo está subdividida em dois momentos, além desta introdução e das considerações finais: no primeiro, a partir de uma revisão da literatura, explicita-se a origem do sindicato e sua importância enquanto organização de trabalhadores, pontuando o trabalho e a participação como categorias. Analisa-se, ainda, a organização das mulheres agricultoras e sua inserção em diferentes espaços sociais até serem associadas e partícipes da entidade sindical, no contexto da organização política; no segundo, a partir da análise documental, realizamos discussões referentes ao modo como essas mulheres se inserem na entidade, pelo modo de sobrevivência no trabalho e nas lutas do próprio sindicato, pautando suas demandas, no intuito de que sejam visibilizadas enquanto agente que como ser, no/e pelo trabalho, também, produz sua existência. Nesse item, trazemos alguns elementos constitutivos da importância da atuação da mulher trabalhadora no seio do movimento sindical e no meio onde vive, concebendo-a como um ser que é capaz de pensar, realizar ações e refletir sobre sua condição de mulher trabalhadora agricultora e associada, dimensões que a constituem como Ser Político.

\section{A constituição da mulher trabalhadora agricultora em Ser Político-Social: Uma perspectiva de participação}

O sentido de participação está ligado ao projeto democrático e ao exercício da cidadania por meio do vínculo entre povo e poder. Para Carvalhaes e Silva (2017, p. 58), "[..] somente através de participação política de todos os cidadãos é que se poderá falar em Estado Democrático de Direito, paradigma indispensável para efetivação de outros direitos fundamentais".

Sendo a participação uma das condições principais ao exercício de cidadania e, por extensão, a participação popular um processo de aperfeiçoamento democrático, os processos participativos nos Estados Democráticos de Direito não podem ser negados. Negar a participação é, pois, transformar homens e mulheres em massa amorfa, pois o aperfeiçoamento democrático se faz por "[...] luta de vontades políticas 
conscientes e responsáveis" (WEFFORT, 1984, p. 31), sendo o sindicato um importante espaço de participação política.

É, pois, nas relações de trabalho que os sindicatos, enquanto organizações ou espaço coletivo de representação de profissionais, como entidade de classes, assumem importância.

Para trazer a categoria de ser político-social, de modo a explicitar o processo de construção da mulher trabalhadora rural no contexto da organização das lutas dos trabalhadores rurais do município de Cametá, é, pois, necessário retratar o trabalho enquanto elemento fundante da materialidade da existência humana, pois, segundo Netto (2010, p. 41), "[...] o trabalho é constitutivo do ser social, mas o ser social não se reduz ou esgota no trabalho. Quanto mais se desenvolve o ser social, mais as suas objetivações transcendem o espaço ligado diretamente ao trabalho".

A criação dos sindicatos, como entidades de classe e como espaços legítimos, segundo Pannekoek (2007, p. 60), “[...] são, pouco a pouco, reconhecidos como representantes dos interesses dos trabalhadores e trabalhadoras e ainda que a luta continue necessária, tornam-se uma força que participa nas decisões". Para o autor, essa entidade nasce da solidariedade dos trabalhadores como necessidade de organizar-se enquanto classe trabalhadora, para enfrentar coletivamente 0 capitalismo como inimigo.

Para Netto e Braz (2010, p. 34), o "[...] trabalho é sempre atividade coletiva: seu sujeito nunca é um sujeito isolado, mas sempre se insere num conjunto (maior ou menor, mais ou menos estruturado) de outros sujeitos". Logo, o caráter coletivo da atividade do trabalho, para os autores, é, substantivamente, aquilo que se denominará social. Todavia, a sistemática do capital individualiza o trabalhador, sendo o sindicato e as demais associações entidades de importância, onde as "[...] mulheres travam, assim, uma luta pela igualdade, pela visibilidade e pelo seu protagonismo, desconstruindo a história tradicional antropocêntrica e universalizante do mito do sexo frágil” (AQUIME, 2018, p. 25).

Netto e Braz (2010) trazem reflexões pertinentes em relação ao conceito de ser social e seu nexo com a formação política, cuja prerrogativa das relações de trabalho constitui o Ser Político. Trata-se de conceber o trabalho em contínua criatividade e evolução, numa dinâmica transformadora da natureza e do próprio homem graças "[...] à sua própria criatividade, ao trabalho" (NETTO; BRAZ, 2010, p. 37). 
Para Cisne e Santos (2018), o trabalho é indispensável à reprodução dos seres humanos, sendo a atividade muito cara à perpetuação da espécie e de sua evolução como ser social, quando se pode dizer que essa marca diferencia os humanos dos animais. O trabalho é, na concepção do Braverman (1976), algo específico do ser humano. Para esse autor, no entanto, apoderar-se dos materiais da natureza tais como são, sem transformá-los, não é trabalho, pois o trabalho é uma atividade que modifica o estado dessa matéria para apurar sua utilidade.

Consideramos que, desde os primórdios, os seres humanos - homens e mulheres -, para garantir sua reprodução precisavam trabalhar. O conceito de trabalho que defendemos é o trabalho formador do gênero humano, ou seja, aquele que satisfaz às necessidades básicas da humanidade, que, por outro lado, promove a qualificação e o aperfeiçoamento de homens e mulheres. Para Cisne e Santos (2018), trata-se da relação dialética, cuja síntese integra o homem, tendo sentido ontológico na medida em que sua importância reside nas relações onde ocorrem o movimento entre o pensar e o agir sobre a natureza, resultando objetivamente sua condição de existência, que é processo onde se materializa na/pela transformação da natureza para garantir a sobrevivência da espécie.

Transformando, assim, a natureza, homens e mulheres, consequentemente, transformam-se, mediados pela necessidade de aprimorar os instrumentos que estes produzem, e que, buscando aperfeiçoá-los, produzem novos instrumentos capazes de dar conta, cada vez mais, de aproveitar seu uso em diferentes atividades.

Nesse sentido, mulheres e homens apropriam-se da natureza segundo suas necessidades, e seu trabalho, para Braverman (1976, p. 49-50), "[...] não transforma apenas o material sobre o que opera; ele imprime ao material o projeto que ele tinha conscientemente em mira, o qual constitui a lei determinante do seu modo de operar e ao que tem de subordinar sua vontade". Assim, o trabalho, como atividade intencional, orientado pela inteligência e esforço físico, é "[...] produto especial da espécie humana. Mas esta, por sua vez é produto especial desta forma de trabalho. Ao agir assim sobre o mundo externo e transformá-lo, ele mesmo modifica sua própria natureza" (BRAVERMAN, 1976, p. 52), criando, recriando, refletindo e aprimorando sua existência, com e pelo trabalho.

Essa evolução realizada por meio trabalho, mediada pelos instrumentos para transformar a natureza e o próprio ser humano, acentuam Netto e Braz (2010), "[...] a 
efetivação do trabalho, [...] só se dá quando essa prefiguração ideal, isto é, quando a matéria natural pela ação material do sujeito é transformada", implicando, pois, em um movimento que exige o planejar e o executar, constituindo, segundo ponderações de Cisne e Santos (2018, p. 27 ), "[...] o trabalho do ponto de vista ontológico, no ato fundante do ser social", que cria, reflete sobre a materialização e recria, melhorando a matéria para satisfazer outras necessidades vitais.

Desse modo, o trabalho, mediante o limiar das sociedades, permitiu a formação do ser social e estruturou a sociedade, objetiva e subjetivamente. Os indivíduos e a sociedade tendem a desdobrar-se mediados por outros sistemas que não buscam mais satisfazer às necessidades vitais, mas à individualidade. É nessa dinâmica que apreendemos a diversidade humana e, nesta, está inclusa a vida da mulher trabalhadora agricultora, seja ela negra, cabocla, indígena ou ribeirinha, cuja essência forjada no/pelo trabalho a transforma em Ser Político.

Essa diversidade de mulher trabalhadora agricultora que a totalidade de associadas no STTR/Cametá abarca é, ao mesmo tempo, singular como partícipes da população amazônica, região marcada por desigualdades diversas, onde, certamente, o peso da cultura de diferença de gênero que privilegia a figura masculina também a afronta. Nesse contexto, a militância representou avanço considerável para as trabalhadoras rurais, tendo sido maioria dentre o conjunto de associados, conforme documento da entidade (CAMETÁ/STTR, 2017).

No referido documento, observou-se um total de 7.837 (sete mil oitocentos e trinta e sete) associados, sendo 1.594 (mil quinhentos e noventa e quatro) homens e 6.243 (seis mil duzentas e quarenta e três) mulheres trabalhadoras rurais. Esse quantitativo representa $79,66 \%$ de mulheres, para $20,34 \%$ homens filiados. Tais dados informam que as trabalhadoras, em sua singularidade, buscam a entidade com maior frequência, seja por necessidade de engajamento no processo produtivo com mais visibilidade entre os demais trabalhadores e/ou como uma alternativa de participação política que ofereça oportunidades de inserção em espaços para além do sindicato.

Pondera-se que esse Ser Político, que é a mulher trabalhadora rural, com marca singular, constrói-se e reconstrói-se, pois é no contexto do sindicato do qual faz parte que se identifica como tal e, nesse caso, de acordo com Hebétte, Magalhães e Maneschy (2002, p. 32), "[...] são grupos sociais que vivem no meio rural, seja na terra 
firme ou na várzea", onde produzem suas existências. O ser social do qual tratamos é trabalhadora rural, reconhecida como agricultora familiar, e sua profissão envolve dimensões multifacetadas, pois é na relação com a natureza que retira as condições de sobrevivência, garantindo o sustento de sua família, tornando-se autônoma na relação com o parceiro e demais sujeitos. As mulheres, segundo Siliprandi e Cintrão (2015, p. 574), "[...] além do trabalho na casa, [...] participam do trabalho na agricultura (preparação do solo, plantio, tratos culturais, colheita, pós-colheita) e também se responsabilizam pelo "quintal'”, como mães, cuidam de seus familiares, na relação com os outros seres humanos, buscam nas organizações evidenciar suas necessidades, e, como associadas, lutam por um espaço no contexto político do sujeito coletivo que congrega sua categoria.

Nesse entendimento, os estudos de Cisne e Santos (2018) sobre diversidade sexual humana e sua relação com trabalho, classe social, ajudam a compreender as lutas das trabalhadoras por um espaço no contexto social e político e na estrutura organizativa sindical, sem uma necessidade pujante de enveredarmos pelas discussões referentes aos feminismos e suas correntes.

Nesta premissa, concordamos que a desvalorização das trabalhadoras foi construída desde os sistemas feudal e escravista até o capitalista, que ocorreu, segundo Cisne e Santos (2018), "[...] no processo histórico, na exploração do homem/ mulher sobre homem/mulher, desde a sua formação embrionária, expressa na origem da propriedade privada". Assim sendo, a exploração do trabalho cimentou os sistemas do racismo e do patriarcado, fazendo com que, na classe de trabalhadores, os homens exercessem esse mesmo sistema de poder sobre as mulheres.

Desse modo, as lutas das mulheres agricultoras não se fazem apartadas das lutas de classe, fração de classe, mas imbricadas a elas, mesmo que, para sua categoria, de forma parcial ou secundária, essas lutas sejam, segundo Paulilo (2010, p. 3), "[...] um produto típico da época dos movimentos sociais no Brasil e apresenta trajetória semelhante a muitos outros destes movimentos", que visa a demandas por reconhecimento de seu trabalho e, posteriormente, a um lugar no espaço político na entidade representativa.

O sindicato dos trabalhadores rurais é considerado um importante canal de interlocução, por isso, consideram-no como "[...] lócus de aglutinação dos agricultores familiares e trabalhadores rurais, aparecendo como espaço de organização e canal 
de veiculação dos (novos) interesses sindicais e políticos dos agricultores e agricultoras familiares" (MALAGODI; BASTOS, 2003, p. 5), como as pautas e agendas das trabalhadoras em constante debate para que seus direitos de participar com voz e voto sejam respeitados.

É nesse espaço que são debatidas temáticas relevantes para fortalecer cada vez mais o sentido de pertença entre os/as associados/associadas e o sindicato. As demandas emergentes devem transformar-se em propostas nas assembleias, conferências, congressos, pautando sempre a problemática da vida dos trabalhadores e das trabalhadoras. E, por se tratar de um movimento que integra inúmeras ideias, também é perpassado por contradição, como relatam Siliprandi e Cintrão (2015, p. 578): as "[...] mulheres enfrentam uma disputa constante para a conquista de espaços e para a inserção e reconhecimento efetivo da questão de gênero no interior das organizações de trabalhadores rurais".

Como parte do segmento de associados no STTR/Cametá, as trabalhadoras, em seus coletivos, partilham experiências e apresentam contrarrespostas aos estigmas que as inferiorizam historicamente, tornando-se aptas às conquistas de espaços de gestão no movimento sindical e para além deste, a exemplo de uma das companheiras que passara a ter assento na $\mathrm{CONTAG}^{8}$, confirmando que a base sindical é um espaço de formação e apropriação de conhecimentos que habilita os seus membros.

As agricultoras, imbuídas de conhecimentos adquiridos pela formação de base, desde a Associação Paraense de Apoio às Comunidades Carentes (APACC), e outros mais, desenvolveram estratégias de resistência em seus coletivos e lugares de pertença, conforme os postulados que propõem Netto e Braz (2010), que é a capacidade de projetar, de pensar antes de realizar a ação. Para os autores, a dimensão que o trabalho proporciona ao indivíduo, em suas complexas dimensões de humanização, linguagem, reflexão sobre o material objetivado, também o transforma. Segundo Netto e Braz (2010, p. 41-42):

$\mathrm{Na}$ sua ação e na sua atuação, o ser social sempre encontra alternativas, sempre pode escolher - e escolha entre alternativas concretas configura exercício de liberdade, ser livre é poder escolher

\footnotetext{
${ }^{8}$ Aqui nos referimos à companheira Waldirene Gonçalves da Cruz, que após militar no STTR/Cametá como Vice-Presidente, conforme documento de posse, de 2010 (STTR/CAMETÁ, 2010) para o mandato de 2010 a 2014, passou a participar de outros espaços, tomando assento na CONTAG.
} 
entre elas: o ser social é um ser capaz de liberdade. Pensar, projetar, objetivar-se e escolher.

A partir do trecho de Netto e Braz que salienta o engajamento do homem/mulher mediado pela ação como ato de liberdade, enfatiza-se a importância de algumas ações das trabalhadoras rurais em projetos, tomando como exemplo o "Grupo de Mulheres Nova Esperança de Cametá" (GMNE/CAMETÁ, 2009). Esses projetos funcionavam nos setores da Estrada e outras localidades como a Comunidade de Livramento, em Cametá e sua ênfase está em ser reconhecido como uma ação que resultou da associação das mulheres, sindicalizadas ou não. Nessas ações, as mulheres conseguiram ampliar e fortalecer suas lutas nessas comunidades e no interior do sindicato.

O Projeto GMNE chegou a um coletivo de 22 (vinte e duas) mulheres agricultoras/es familiares e 1 (um) homem na mesma categoria, não sendo uma associação exclusiva de mulheres, mas com maior visibilidade feminina, sem deixar de "[...] considerar alguns aspectos específicos entre os sexos, como classe social, pois tanto homens quanto mulheres fazem parte do grupo menos favorecido" (AQUIME, 2018, p. 17), quando se trata de trabalhadores.

Considerar, pois, o processo formativo do ser político-social como inconcluso e permanente, sempre aberto às possibilidades, é considerar a necessidade de constante aperfeiçoamento e, nisso, consiste a formação da mulher associada, tornando-a "[...] apta a reconfigurar-se, e enriquecer-se no curso da história presente e futura" (NETTO; BRAZ, 2010, p. 42). O permanente refletir do grupo de trabalhadoras no processo participativo das ações da base, por meio da Federação Estadual dos Trabalhadores na Agricultura (FETAGRI), por exemplo, foi uma das formas de construir modos de sustentabilidade, resistindo às ações que degradam o meio ambiente, quando estas participaram do "Projeto na Amazônia Empreendedorismo das mulheres Rurais do Pará".

O relatório de ações desenvolvidas nesse projeto pelo grupo de mulheres sugere que é na organização do coletivo que elas mobilizam ideias sobre o desejo de desenvolver um trabalho de fortalecimento e preservação do meio ambiente, tanto pelos vínculos de pertencimento à terra quanto pelo trabalho como forma de resistência aos projetos desenvolvimentistas pragmáticos que intencionam exclusivamente resultados como bens de troca, mercadorias. 
Pela práxis humana "[...] os indivíduos constroem a si mesmos e a totalidade social, e que ela é a fonte da constituição do ser social, ou da autoconstrução humana e, também, a partir dela ocorre o desenvolvimento as relações sociais" (CISNE; SANTOS, 20015, p. 28), promovendo interações que permitem propiciar momentos de encontros, de trabalho, e de contínuas elaborações e refinamentos das atividades desse coletivo em constantes elaborações e reelaborações de estratégias de enfrentamentos que permeiam suas atividades, tanto no fazer agrícola como externo a ele.

Com base nas ideias de Cisne e Santos (2018), de que as relações de gênero não se dissociam das lutas políticas e de classes, podemos retratar o projeto Grupo de Mulheres Nova Esperança de Cametá (GMNE/CAMETÁ, 2009), projeto que representou para as associadas um espaço de desenvolvimento de ações/produção de subsistência por meio de iniciativas protagonizadas por elas com assessoria técnica de órgãos competentes e financiamento por programas específicos. Nessa iniciativa, as associadas demonstraram seu potencial criativo de agricultoras, por ações de viveiros de mudas para o plantio de 10.000 (dez mil) mudas de árvores, tanto de espécies nativas da região quanto de árvores frutíferas - como cacau, açaí, cupuaçu, graviola, acerola, goiaba e outras.

Assim, a formação política como militantes e a condição de mulher e de trabalhadoras rurais integram-se para a constituição desse ser social mais consciente de seu papel. Esse modo de atuação e de organização por meio da entidade sindical é uma forma de resistir, existir e participar, considerando a necessária defesa de "[...] interesses da classe que não detém o mecanismo de produção, como a sua fração que habita e constitui na Amazônia” (SILVA, 2011, p. 89).

As trabalhadoras, segundo o documento "Grupo de Mulheres Nova Esperança de Cametá" (GMNE/CAMETÁ, 2009), se declaram agricultoras familiares, reconhecendo sua categoria e a importância que estas tencionam nesses espaços, tornando possível uma interpretação apoiada em Netto e Braz (2010) que, por meio do trabalho, pode-se transcender para outras objetivações imediatas, enquanto mulher trabalhadora rural, como aquisições da filosofia, da arte, da agroecologia, bem como o ensejo de ser mais, SER político e dirigente.

Do coletivo de mulheres agricultoras familiares ressoa um agradecimento todo especial às entidades que Ihes deram fôlego para fomentar formas de construir modos 
de resistência frente à produção que degrada o meio ambiente, como expressa o documento Grupo de Mulheres Nova Esperança de Cametá. (GMNE/CAMETÁ, 2009): "Queremos agradecer à FETRAGRI-PA e SAGRI, que estão trabalhando este projeto de desenvolvimento para o Estado do Pará, onde uma nova vida é possível". Essa atividade promoveu a congregação de mulheres em busca não só de geração de renda, mas também uma forma de visibilizar seu trabalho como produtivo e garantir para as futuras gerações as riquezas naturais, concebidas como bens comuns, contrariando a única e perversa lógica de produção que intenta o capital.

É esse contexto de lutas, resistências, estratégias e apropriações de conhecimentos que constitui o processo constante de constituição de Ser Político, no qual a mulher, conscientemente, começa a se declarar trabalhadora agricultora, sendo capaz de construir estratégias de enfrentamento nas relações estabelecidas, mostrando-se sujeito de direitos, ainda que, na prática, suas ações sejam mais experienciadas ou pragmáticas do que juridicamente reconhecidas, conforme veremos no item seguinte.

\section{O processo de organização e participação da mulher trabalhadora agricultora no STTR/Cametá}

O reconhecimento da condição de mulher e de trabalhadora rural foi, talvez, um dos objetivos da militância das associadas na entidade sindical, tendo estas se organizado em diversas mobilizações para que pudessem ter acesso a lugares de visibilidade, pela pertença à sociedade, como cidadãs, pleiteando espaços em outras instituições. É, pois, na mediação do trabalho e nas suas múltiplas relações que nos reconhecemos como classe, quando os indivíduos se constituem seres políticos. Cisne e Santos (2015, p. 28) ressaltam que na relação forjada, "[...] pelo trabalho, os indivíduos constroem a si mesmos e a totalidade social, e que ela é a fonte da constituição do ser social, ou da autoconstrução humana [...]", promovendo interações que permitem propiciar momentos de encontros, de trabalho e de contínuas elaborações e refinamentos das atividades desse coletivo.

Enquanto associadas, a apropriação de conhecimentos de militantes possibilitou um movimento das trabalhadoras agricultoras em direção aos direitos de cargos na estrutura sindical, no sentido de se fazerem presentes em espaços deliberativos. $O$ documento do " $3^{\circ}$ Congresso do Sindicato dos Trabalhadores Rurais 
de Cametá - filiado à Central Única dos Trabalhadores (CUT)", realizado de 22 a 24 de julho de 1997, registra em seu relatório que foi deliberado, nesse encontro, a criação da Comissão de Organização das Companheiras, que teria a composição de 2 (duas) representantes, que seriam escolhidas dentre alguns setores de atuação de movimento de mulheres de Cametá, conforme quadro abaixo:

Setor Estrada: Helena - (Ajó); Suely - (Cupijó); Setor Cima: Margarida (Merajuba); Orlandina - (Cuxipiari Furo Grande); Setor Médio: Gigita, Francisca da Conceição (Carapajó); Raimunda da Conceição; Setor Baixo: Claudina, Maria Zula; Cidade: Anádia, Elza, Adede (CAMETÁ/STR, 1997, p. 9).

Esse documento define o papel das comissões constituídas, que seria o de organizar as trabalhadoras e de promover discussões com elas sobre as demandas que deveriam pautar no contexto sindical. Para Leone e Teixeira (2010, p. 4), "[...] a criação de comissões de mulheres nas estruturas sindicais deu-se a partir da necessidade de introduzir no movimento sindical a luta da mulher trabalhadora para enfrentar a discriminação a que são submetidas no cotidiano do trabalho, do sindicato, e na realidade como um todo".

A criação da Comissão de Organização das Mulheres como pauta do seminário acima citado foi, sem dúvida, um momento oportuno para a entidade sindical problematizar a condição desse segmento de trabalhadores em relação à sua inserção enquanto mulher no contexto da diretoria do Sindicato, com importante papel a desempenhar e considerável influência. Sobre a participação das mulheres em organizações como trabalhadoras Silva (2008, p. 15), afirma:

[...] a participação no movimento dos agricultores não era motivada por reivindicações específicas de sua condição de mulher; o que as mobilizava era o reconhecimento de pertencer a determinada categoria social e política, integrando, assim, o conjunto de lutas pelo direito à terra, ao crédito e aos benefícios da previdência social como aposentadoria e auxílio doença.

Por meio de sua organização, essas mulheres, no caso do STR/Cametá, que eram também invisíveis no plano político, passaram a conhecer seus principais direitos e a reconhecê-los como legítimos, como o auxílio-maternidade e o financiamento de atividades agrícolas por parte dos investidores e bancos credores e, em outros espaços, como a inserção de uma trabalhadora na composição da diretoria 
do Sindicato, no mandato de 1997 a 2000, assumindo a Secretaria de Finanças, conforme o documento analisado (CAMETÁ/STR, 1997, p. 10).

No entanto, no mandato de 2000 a 2004, verificou-se que a organização das comissões por setores tomou outra configuração, reduzindo o número de lideranças femininas em setores do sindicato que antes eram por elas liderados e nos quais buscavam ampliar seus espaços de participação, sem que isso tivesse enfraquecido a participação sindical das mulheres. A partir do ano de 2000, das 12 (doze) mulheres existentes nas comissões setoriais sindicais, apenas 2 (duas) delas assumiram posição de liderança. Esse fato é ilustrado no documento Projeto de Formação de Convênio e Cooperação com a Alemanha - DED Deutscher Entwicklungsdienst, Serviço Alemão de Cooperação Técnica e Social - EO/21/2002 (EO/BRASIL, 2002), que registra os nomes de Suely da Assunção N. da Silva e Helena Ferreira da Cruz, que dentre as associadas assumiram cargos de Secretária na Secretaria da Mulher/STR/ Cametá e Secretária da Secretaria de Gênero e Geração, respectivamente, em mandatos ocorridos no recorte histórico analisado.

A inserção das companheiras como lideranças na estrutura sindical possibilitou organizar demandas em busca de caminhos viáveis para participação de modo qualificado nesse contexto. E o "Projeto de Formação da Secretaria de Mulher do STR", em convênio com a ONG Alemã, financiou a formação das trabalhadoras no mandato entre os anos 2000 e 2004. Contudo, a Secretaria de Mulher somente se configura como tal após adentrar na pauta de discussões, como foi apurado na Proposta para Debates do $6^{\circ}$ Congresso do STR 2006: "Consolidar a Secretaria de Mulher no STR" (CAMETÁ/STR, 2006, p. 5), fazendo composição de forma legitimada por meio do $6^{\circ}$ Congresso do STR, onde duas trabalhadoras passaram a fazer parte dessa composição, desde o mandato do ano 2000.

Se, por um lado, as mulheres se organizam e mobilizam esforços para conquistar espaços nessa entidade - que se inicia com as Comissões de Companheiras, Coordenadoria, até a consolidação da Secretaria da Mulher -, no interior do movimento, por outro lado, confrontam-se com os encaminhamentos e prioridades desse sujeito coletivo que é o sindicato, com caráter relativamente estável e que tem a função de defender os interesses do conjunto de associados, muitas vezes, impossibilitando os encaminhamentos em relação à questão de gênero, pois "a história das trabalhadoras rurais no Brasil é marcada pela exclusão. Exclusão que 
se somou durante muito tempo a sua condição de classe explorada e marginalizada, com uma forte discriminação de gênero" (OLIVEIRA, s/d, p. 5).

É, pois, a busca de uma formação política que as mulheres empreendem na militância e nas mobilizações como mecanismo de superação da discriminação. A partir das leituras de Silva (2019), pondera-se que tais discriminações são uma forma de subjugar e silenciar as possibilidades femininas, às vezes, de forma velada, individual ou nas "[...] relações em sociedade que trazem uma série de complexidades, dentre elas, as relações de poder e suas contradições, na qual o poder se dá na relação entre os indivíduos na prática social cotidiana. (SILVA, 2019, p. 2098).

Em contestação aos modos dirigentes no movimento sindical, as trabalhadoras rurais empreenderam plenárias nos diversos setores que compunham as delegacias frente às demandas por uma plataforma para a Secretaria de Mulher. Esse movimento está contido no documento do Projeto I Seminário de Mulheres Trabalhadoras Rurais STTR 2005, com objetivo de "Discutir a Relação de Gênero na Agricultura Familiar, dentro do Sindicato dos Trabalhadores e Trabalhadores Rurais de Cametá" (CAMETÁ/STR, 2005c, p. 4).

No referido documento, verificamos que as mulheres trabalhadoras eram maioria como associadas, mas política e socialmente elas apresentavam limitações em relação aos homens tanto nos espaços de lideranças nos cargos de diretorias da entidade, quanto nos demais espaços de produção, como na agricultura familiar, onde a força de trabalho destas, ainda que considerada importante, não havia registro de liberação ou apoios financeiros à mulher junto aos órgãos competentes. Esse limitado reconhecimento da mulher associada é ilustrado no seguinte trecho: "Hoje a mulher é maioria dentro do STR de Cametá, entretanto, na prática isso não se transporta para os debates internos, ficando-a sempre em segundo plano, onde as mulheres estão em todos lugares e não estão em lugar nenhum" (CAMETÁ/STR, 2005c, p. 2).

Dessa maneira, percebe-se que, tanto no trabalho da roça quanto na sua inserção no movimento sindical, a mulher não é reconhecida, ainda que ela tenha importância para o desenvolvimento pessoal e coletivo. Essa reflexão que mostra o amadurecimento que elas alcançaram diante das lutas é consciência de si, que elas conseguem externar nesse projeto, pois, para Cappellin (1994, p. 279), quando elas

[...] conseguem fazer própria uma reflexão que articula uma luta contra a discriminação por sexo nos locais de trabalho com uma demanda visando romper a assimetria nas relações de poder no interior das organizações sindicais, esta contínua mediação entre as 
especificidades da condição de produtora e a subordinação nas relações de poder faz com que se afirme que os movimentos problematizam o interesse das mulheres de querer exercitar a representação nas instâncias sindicais.

Em relação à discriminação e à inferiorização intramovimento, em especial à mulher trabalhadora, é "[...] preciso compreender, portanto, que as classes não são abstrações, mas que resultam de relações sociais concretas [...] que são marcadas por ideologias, que naturalizam inferiorizações e desvalorização em torno de sua diversidade" (CISNE; SANTOS, 2018, p. 75). Em detrimento a essas invisibilidades, segundo a CONTAG $(2011$, p. 48$)$, , [...] as mulheres assumem a necessidade de adotarem as políticas afirmativas, para que sua participação seja qualificada e tenham igualdade de condições em relação aos companheiros".

Em contrarresposta à hegemonia masculina que se acentuava no contexto político e nos direcionamentos dos caminhos tomados nesse movimento, as mulheres demandam diretrizes para orientar as relações de gênero, conforme o documento "Relatório do $3^{\circ}$ Congresso do Sindicato dos Trabalhadores Rurais de Cametá Filiados à CUT - Resistir, Avançar e Vencer" (CAMETÁ/STR, 2005b, p. 3):

[...] para construirmos novas relações de gênero faz-se necessário descruzarmos os braços e sair a luta, para isso a secretaria das mulheres do STTR de Cametá, [...] está construindo uma plataforma e diretrizes norteadoras das relações de gênero dentro do Sindicato dos Trabalhadores e Trabalhadoras Rurais - STR's e da sociedade do Baixo Tocantins. ${ }^{9}$

Outro movimento que proporcionou debates em relação às demandas específicas da mulher foi a apresentação do tema relacionado à violência contra a mulher. Pelo documento sobre o Fórum de Mulheres da Amazônia Paraense (2006), evento esse que foi divulgado e mobilizado pela Secretaria de Mulher, em parceria com a Diocese de Cametá/PA, verificou-se que foi debatido o tema de modo geral e realizada roda de discussão para maior apropriação dos conhecimentos pelas mulheres do campo. O documento deixa claro que a "violência contra a mulher" fez parte da pauta do encontro como tema alusivo ao "8 de março - Dia Internacional da Mulher" (BELÉM/FMAP, 2006, p. 2). As discussões, segundo o referido documento, potencializariam as mudanças principais previstas na lei protetiva da mulher.

\footnotetext{
9 Não tivemos acesso a essas proposições, nem conseguimos determinar se tal plataforma foi elaborada.
} 
Reiteramos que as mobilizações, sejam nas organizações sindicais ou para além destas, mostram-se importantes, pois a "[...] troca entre culturas diversas possibilita renovar as concepções de fazer política" (CAPPELLIN, 1994, p. 277).

Fruto das mobilizações das associadas, foi criada a Secretaria de Mulher, como um dos espaços importantes de liderança feminina no interior do sindicato. Em articulação com outros órgãos, como a Federação dos Trabalhadores Rurais Agricultores e Agricultoras Familiares do Estado do Pará (FETAGRI-PA) - órgão vinculado à Central Única dos Trabalhadores (CUT) -, com papel importante na defesa dos direitos do trabalhadores/as rurais contra a ofensiva assustadora do grande capital, e com o Banco da Amazônia (BASA), a Secretaria de Mulher passou a discutir a questão de gênero, e a incentivar as trabalhadoras na superação das desigualdades de condições de produção no meio rural, por exemplo, por financiamento do PRONAF MULHER ${ }^{10}$.

A Ata de Posse da Diretoria do STR - quadriênio 2010-2014 -, quando a trabalhadora senhora Waldirene Gonçalves da Cruz assumiu a Vice-direção, registra emblematicamente que os avanços e as conquistas das associadas se deve também à aquisição de saberes pertinentes de formação apropriada pelas lideranças de trabalhadoras, haja vista que o sindicato proporcionou formação para os trabalhadores e para as trabalhadoras lideranças, em parceria com a Casa Familiar, no sentido de promover a educação básica, e, em outros eventos, a formação política e sindical, embora os documentos analisados deixem evidente que as trabalhadoras eram sempre minoria nos momentos formativos propiciados pela entidade.

As diretorias e cargos de mandatos assumidos pelas mulheres no Sindicato, sem dúvida, foram um avanço importante para o aperfeiçoamento democrático da entidade, não apenas por representar a ruptura de uma cultura estabelecida de permanência de lideranças e/ou dos cargos alternados entre os homens, em até três mandatos consecutivos, mas pela presença feminina nesse espaço. Para Cisne e Santos (2018), é importante relacionar a luta das mulheres como um movimento legítimo contra as desigualdades vinculadas à classe trabalhadora.

Os mandatos com permanência de lideranças que asseguraram a mesma composição da diretoria do sindicato ou a alternância entre seus membros com a

\footnotetext{
${ }^{10}$ Financiamento que visa atender as propostas de crédito de mulheres agricultoras, conforme projeto técnico ou proposta simplificada.
} 
prevalência dos homens associados como líderes, até três mandatos consecutivos, não se revelaram atrativos para o funcionamento da entidade. Segundo as fichas de filiação dos associados, entre os anos de 1999 e 2010 - período de recorrência desse tipo de posição político-administrativa -, verificou-se baixa taxa de sindicalização por parte das trabalhadoras mais jovens. Do total de filiadas, apenas $0,77 \%$ delas tinham entre 20 e 29 anos (CAMETÁ/STR, 2010).

A nossa defesa é, pois, por um novo sindicato, transparente e participativo, com potencial para articular seus membros em torno dos interesses destes enquanto categoria, fortalecendo-os em sua representatividade. Enfim, postula-se um espaço onde se possa respeitar e valorizar homens e mulheres trabalhadores/as com particular atenção à singularidade feminina, como trabalhadora e agricultora rural, que é uma tarefa a mais na sua condição de mulher.

\section{Considerações finais}

Para trazer as ideias conclusivas da pesquisa que deu corpo ao presente texto, retomemos o objetivo inicial da investigação - analisar o papel da mulher agricultora na entidade sindical STTR/Cametá, tendo em vista os limites da sua atuação de associada e as possíveis conquistas que a tornaram Ser Social politicamente mais engajada, a partir deste movimento sindical. Cremos, pois, que, só a partir de então, é que podemos destacar os argumentos centrais que foram produzidos desde os conceitos mais gerais às dimensões específicas das análises sobre os dados dos documentos que estudamos.

Importante destacarmos que as trabalhadoras agricultoras têm uma reivindicação comum à de todos os trabalhadores do campo, cujos direitos passaram a ter visibilidade na agenda governamental, quando o Estado passou a reconhecer os direitos dessa categoria de sujeitos em termos previdenciários, direito à terra, crédito agrícola, dentre outros. Todavia, ainda que esses direitos estejam formalmente garantidos, os acessos efetivos são lentos e bastante restritivos, razões primordiais que levam as trabalhadoras a construírem estratégias variadas e caminhos para conquistar tais reivindicações e outras mais específicas às suas condições de mulher.

Nesse processo de luta, fez-se necessário o enfrentamento da desigual oportunidade dessas trabalhadoras por meio da organização sindical, para que, além 
de associar-se à entidade passando a ser sócia legítima, elas pudessem ainda obter o reconhecimento de mulher trabalhadora, Ser Político. Buscavam, nessa condição, reconfigurar suas estratégias para atuar em prol da defesa de suas reais necessidades que, segundo Silva (2008), era o de pertencimento a essa categoria social e política, e, assim, integrar-se às lutas relativas ao direito à terra e por fomentos agrícolas, bem como por outros benefícios que, no decorrer das demandas sociais, vão sendo adquiridos.

Uma das estratégias dessas trabalhadoras foi pautar suas reivindicações nesse movimento sindical, antes STR/Cametá e atual STTR, onde sua inserção na estrutura política do sindicato foi, talvez, um meio de romper com a assimetria de poder, no contexto desse movimento predominantemente marcado pelo domínio masculino. De acordo com Cappellin (1994), associar-se ao sindicato foi, dentre outras, uma das maneiras encontradas para problematizar o interesse das trabalhadoras agricultoras, passando a exercitar a representação nas instâncias sindicais e, consequentemente, um meio de expor suas condições e especificidades enquanto produtoras pertencentes a essa categoria de trabalhadoras/es.

É nesse cenário de lutas desempenhadas por esses sujeitos sociais, tanto na militância do sindicato, quanto na organização de produção agrícola propriamente, onde ocorreu a constituição desse Ser Político pelo reconhecimento da existência dessas mulheres, pois o trabalho é o que caracteriza o ser social, mas o ser social não se reduz ou esgota no trabalho, mas o transcende (PAULO NETTO, 2010). Importante lembrar a mediação entre trabalho e humanização, uma vez que, à medida em que o homem produz sua existência por meio do trabalho, este transforma a natureza, sendo ele também transformado nessa relação. O trabalhador é, assim, igualmente aprimorado nessa relação, sendo potencialmente capaz de transcender o espaço imediato no/pelo trabalho.

Por meio desse movimento, as trabalhadoras apropriaram-se de conhecimentos relevantes à sua sobrevivência e à continuidade de suas demandas, transcendendo as lutas para outros espaços, de modo a consolidarem seus projetos, como ocorreu com as trabalhadoras do Grupo de Mulheres de Nova Esperança, que foi uma organização de mulheres para além do STTR/Cametá. Essa dinâmica possibilita o que Netto (2010) considera como Ser politicamente engajado. Trata-se de sujeitos imbuídos de conhecimentos em processos de aperfeiçoamento, que 
transcendem o espaço ligado diretamente ao trabalho para outras dimensões, como a política, as artes e a filosofia; nesse caso, a dimensão política da estrutura sindical dos trabalhadores agricultores e das trabalhadoras agricultoras de Cametá.

$O$ engajamento da mulher trabalhadora agricultora como associada foi, sem dúvida, quantitativamente expressivo no período analisado. Apuramos, neste estudo, que, do total de filiados à época, as trabalhadoras correspondiam a $79,66 \%$, ou seja, as mulheres eram maioria na relação com os homens sindicalizados, ainda que estas se limitassem às ações mais gerais da entidade. Essa situação meramente quantitativa da presença da mulher no sindicato não garantia êxito desejado nas lideranças e nem nas conquistas. Suas demandas mais urgentes não eram visíveis, de modo a transformar-se em pautas das assembleias, haja vista as dificuldades de convencimento da importância do trabalho da mulher pelas fragilidades nas relações estabelecidas no contexto político. O limitado alcance do poder não garantia a mudança de qualidade de vida almejada, ainda que a busca de novas possibilidades para equacionar ou minimizar as desigualdades de oportunidade entre trabalhador e trabalhadora rural tenham sido garantidas de forma limitada no processo de engajamento como associadas no atual STTR/Cametá. No entanto, a busca de formação em suas bases para atuar e, assim, fortalecer-se enquanto lideranças pelo sentimento de pertença ao sindicato, foi um fato observado na organização das associadas.

É impossível invalidar o processo de participação política assumido pelas mulheres nesses espaços analisados, apenas considerando a não participação das trabalhadoras em cargo de liderança de alto escalão na entidade e a autonomia limitada das companheiras que conseguiram cargos nas diretorias da mesma entidade. O contraditório movimento no qual suas proposições e reivindicações, por vezes consideradas prioritárias pela executiva da entidade e, muitas vezes, sem chegar a entrar nas pautas, foram alternâncias conjunturais de mandatos que só serviram para fortalecer suas lutas.

O limitado espaço de liderança, de poder e de conquistas das trabalhadoras associadas não invalida a experiência de militância no STTR. Através dessa participação, temas como propriedade da terra, educação e igualdade de gênero passaram a ser pautas do movimento, pois esses temas são relevantes e estão diretamente relacionados à vida e à dignidade como trabalhadoras. 
Apoiadas em Siliprandi e Cintrão (2015), insistimos, afirmando que, para o enfrentamento de possíveis resistências ao ser particular, faz-se necessário um constante embate que subsidie a conquista de espaços, inserção e reconhecimento contínuo, em particular, da questão de gênero. Reitera-se, ainda, a importância de organizações de trabalhadores e trabalhadoras rurais, sendo a mulher associada mais que contribuinte, e sim "ser politicamente engajado", graças às mediações que se estabelecem no trabalho.

As estratégias de organização das trabalhadoras para sua constituição em ser político no contexto do movimento sindical é processual. O estudo revelou que as trabalhadoras rurais associadas ao STTR/Cametá têm, ainda, uma participação limitada no sentido de demandar e aprovar pautas que fomentem dimensões que permeiam sua existência como ser político. A sua militância, no entanto, demarca novos espaços, seja como provedoras de saberes ou de vivências em seus territórios sob outro "olhar".

Enfim, ao mesmo tempo em que a participação limitada pela condição feminina não as impediu de se constituírem como um novo Ser Político, verificou-se, também, que potencialmente sua singularidade de mulher foi capaz de apontar rumos para a emancipação e constituição cidadã com ensejos de tornar a sociedade plural e democrática.

\section{Referências}

ALMEIDA, R. Amazônia, Pará e o mundo das águas do Baixo Tocantins. Estudos avançados, v. 24, n. 68, 2010. Disponível em: https://www.researchgate.net/ publication/250982759_Amazonia_Para_e_o_mundo_das_aguas_do_Baixo_Tocanti ns/link/039990e90cf2f321f131b5ea/download. Acesso em: 17 jul. 2020.

AQUIME, M. S. P. A Luta pela Igualdade de Gênero nos Movimentos Sociais: A criação da cooperativa das mulheres como espaço de luta, resistência e visibilidade no Município de Cametá. 2018. 108f. Dissertação (Mestrado em Antropologia), Programa Pós-Graduação em Sociologia e Antropologia, Universidade Federal do Pará, Belém.

BELÉM/FMAP. Fórum de Mulheres da Amazônia Paraense. Belém, 2006. Disponível em: http://forumdemulheresdaamazoniaparaense.blogspot.com. Acesso em: 08 jun. 2018.

BRAVERMAN, H. Trabalho e Capital Monopolista. Rio de Janeiro: Zahar, 1976. 
CAMETÁ/STR. Relatório do 3 Congresso do Sindicato dos Trabalhadores Rurais de Cametá, filiado à Central Única dos Trabalhadores (CUT). Cametá, PA, 1997.

. Projeto de Formação do STR. Cametá, PA, 2002.

Brasil. Cametá, PA, 2005a.

Projeto de Desenvolvimento Rural do município de Cametá. Relatório do Encontro de Delegada e Delegados. Cametá, PA, 2005b. Cametá, PA, 2005c.

Projeto I Seminário de Mulheres Trabalhadoras Rurais STR. . Documento sobre Fórum de Mulheres da Amazônia Paraense. Cametá, PA, 2006.

Cametá, PA,

Ata de posse da Diretoria do STR. Quadriênio de 2010/2014. 2010.

Ata de alteração estatutária do Sindicato dos Trabalhadores Rurais de Cametá STR. Cametá, PA, 2015.

CAPPELLIN. P. Viver o sindicalismo no feminino. Estudos Feministas, ano 2, p. 271290, $2^{\circ}$ sem. 1994. Disponível em: https://periodicos.ufsc.br/index.php/ref/ article/view/16110/14824. Acesso em: 20 dez. 2019.

CARVALHAES, R B.; SILVA, F. P. da. Democracia, cidadania e mecanismos de participação popular. Revista de Teorias da Democracia e Direitos Políticos, v. 3, n. 2, p. 48-67, jul./dez. 2017. Disponível em: https://indexlaw.org/index.php/revistateoriasdemocracia/article/view/2296. Acesso em: 17 jul. 2020.

CASTRO, M. G. Gênero e Poder no Espaço Sindical. Revista Estudos Feministas, v. 3, n. 1, p. 29-51, 1995 . Disponível em: https://periodicos.ufsc.br/ index.php/ref/article/view/16913. Acesso em: 03 abr. 2018.

CELLARD, A. A análise documental. In: POUPART, Jean et al. A pesquisa qualitativa: enfoques epistemológicos e metodológicos. Tradução: Ana Cristina Nasser. Petrópolis, RJ: Vozes, 2008.

CISNE, M.; SANTOS, S. M. M. dos. Feminismo, Diversidade Sexual e Serviço Social. São Paulo: Cortez, 2018.

CONTAG. Margaridas na luta por desenvolvimento sustentável com justiça, autonomia, igualdade e liberdade. Cadernos de textos para estudos e debates, 2011. Disponível em: http://www.contag.org.br/imagens/fcaderno_textos_marcha_ 2011.pdf. Acesso em: 08. abr. 2019. 
EO/BRASIL. Projeto de Formação de Convênio e Cooperação com a Alemanha DED Deutscher Entwicklungsdienst - Serviço Alemão de Cooperação Técnica e Social. [s.l.], 2002.

GIULIANI, P. C. Os Movimentos de Trabalhadoras e a Sociedade Brasileira. In: DEL PRIORE, M. (org.); BASSANEZI, C. História das mulheres no Brasil. 7.ed. São Paulo Contexto, 2004. Disponível em: http://centrovictormeyer.org.br/.../Cem-anosde-lutas-da-classe-operária1880-1980-Vito-Gi. Acesso em: 10 fev. 2018.

GMNE/CAMETÁ. Grupo de Mulheres Nova Esperança de Cametá. Cametá, PA, 2009.

HEBÉTTE, J.; MAGALHÃES, S. B.; MANESCHY, M. C. (org.). No mar, nos rios e na fronteira. Faces do campesinato no Pará. Prefácio Maria da Conceição D'Incao. Belém: EDUFPA, 2002.

LEONE, E. T; TEIXEIRA, M. O. As mulheres no mercado de Trabalho e na Organização Sindical. [s.l.], 2010. Disponível em: http://www.abep.nepo.unicamp.br/encontro2010/docs_pdf/tema_8/abep2010_2200.p df. Acesso em: 24 jun. 2017.

MALAGODI, E.; BASTOS, V. de S. Sindicato de Trabalhadores Rurais e Agricultura Familiar. In: CONGRESSO BRASILEIRO DE SOCIOLOGIA, 11., 1 a 05 de setembro de 2003, Campinas, SP. Anais eletrônicos [...]. Campinas, SP: UNICAMP, 2003. Disponível em: http://www.sbsociologia.com.br/portal/index.php? option=com_docman\&task=doc_download\&gid=1312\&ltemid=171. Acesso em: 10 fev. 2018.

MINAYO, M. C. de S. O desafio da pesquisa social. In: MINAYO, M. C. de S. (org.); DESLANDES, S. F.; GOMES, R. Pesquisa Social: Teoria Método e Criatividade. Petrópolis, RJ: Vozes, 1994.

NETTO, J. P.; BRAZ, M. Economia Política: uma introdução crítica. São Paulo: Cortez, 2010.

OLIVEIRA, M. R. do C. As Trabalhadoras Rurais Sem Terra e a Questão de Gênero no contexto da Luta pela Terra no Assentamento Nova Ipiranga. Disponível em: http://www.uesc.br/eventos/cicloshistoricos/anais/maria_rosa_do_

carmo_oliveira.pdf. Acesso em: 17. jul. 2020.

PANNEKOEK, A. A Revolução dos Trabalhadores. [s.l.]: Barba Ruiva, 2007. Disponível em: http://www.afoiceeomartelo.com.br/posfsa/Autores/Pannekoek, Anton/ A revolucao dos trabalhadores.pdf. Acesso em: 10 fev. 2018.

PAULILO, M. I S. Movimento de Mulheres Agricultoras: terra e matrimônio. [s.I.], 2010. Disponível em: http://nafa.paginas.ufsc.br/files/2010/08/mma1.pdf. Acesso em: 26 jun. 2019. 
SILIPRANDI, E.; CINTRÃO, R. Mulheres rurais e políticas públicas no Brasil: abrindo espaços para o seu reconhecimento como cidadãs. In: GRISA, C.; SCHNEIDER, S. (org.). Políticas públicas de desenvolvimento rural no Brasil. Porto Alegre: Editora da UFRGS, 2015. (Série Estudos Rurais). Disponível em: http://aspta.org.br/2015/10/ livro-politicas-publicas-de-desenvolvimento-rural-no-brasil. Acesso em: 29 out. 2017.

SILVA, Adriane dos Prazeres. Luta pela posse da terra na Amazônia Tocantina: Trabalhadores Rurais em ação e suas parcerias com a igreja progressista (19791991). In: PAZ, Adalberto Júnior Ferreira, CARDOSO, Antonio Alexandre Isidio; FERREIRA, Lara Vanessa de Castro (org.). Trabalhadores, Migrações e Natureza no Brasil Equatorial. Macapá: UNIFAP, 2018. Disponível em https://www2.unifap.br/ editora/files/2018/05/Livro-Trabalhadores-Migra\%C3\%A7\%C3\%B5es-e-Natureza-noBrasil-Equatorial.pdf. Acesso em: 27 abr. 2020.

SILVA, M. R. Gênero, desigualdades e agricultura: a mulher na atividade agrícola familiar. Braz. J. of Develop., Curitiba, v. 5, n. 3, p. 2095-2105, mar. 2019. Disponível em: https://www.brazilianjournals.com/index.php/BRJD/article/view/1227. Acesso em: 18. jul. 2020.

SILVA, M. E. P. da. Socialização de agricultoras no movimento de mulheres do Nordeste Paraense. 2008. 92f. Dissertação (Mestrado em Agriculturas Familiares e Desenvolvimento Sustentável) - Programa de Pós-Graduação em Agriculturas Amazônicas, Núcleo de Ciências Agrárias e Desenvolvimento Rural, Universidade Federal do Pará; Empresa Brasileira de Pesquisa Agropecuária - Amazônia Oriental, Belém, 2008. Disponível em: http://ppgaa.propesp.ufpa.br/ ARQUIVOS/dissertacoes/2008/MARIA_EVANEIDE_PANTOJA_DA_SILVA.pdf. Acesso em: 02 abr. 2019.

SOUZA, E. de. A participação das trabalhadoras agricultoras no STTR / CAMETÁ: Trajetória histórica, lutas e constituição da mulher em SER SOCIAL. 2019. 157f. Dissertação (Mestrado em Educação e Cultura), Programa de Pós-Graduação em Educação e Cultura, Campus Universitário do Tocantins/Cametá, Universidade Federal do Pará, Cametá, PA, 2019.

WEFFORT. F. C. Por que democracia? 2ª ed. São Paulo: Brasiliense, 1984. 